\title{
EDUCAÇÃO DE JOVENS E ADULTOS E A TELEVISÃO ABERTA: UM OLHAR DOS ALUNOS DE UMA ESCOLA PÚBLICA NO ESTADO DA BAHIA
}

\author{
Renata Souza dos Santos ${ }^{1}$ \\ Albano de Goes Souza ${ }^{2}$
}

RESUMO: Este artigo tem por objetivo discutir a relação que os alunos do $5^{\circ}$ e $6^{\circ}$ anos da modalidade EJA (Educação de Jovens e Adultos) da Escola Austricliano Carvalho têm com a Televisão Aberta, uma vez que, por estes estudantes ainda não terem escolarização completa e pertencerem às classes menos favorecidas se tornam vulneráveis às influências midiáticas. As reflexões presentes nesse texto têm por base não apenas o estudo teórico ou referências, mas, parte da análise de dados coletados no processo do estudo de caso dentro de uma abordagem qualitativa. Participaram como sujeitos da pesquisa o7 (sete) alunos da EJA. Foi utilizado como instrumento de coleta de dados a entrevista semiestruturada feita individualmente com cada um dos participantes. Os resultados obtidos apontam que os alunos têm uma relação de educação informal em relação à Televisão Aberta, tornando-se também como alternativa de lazer.

Palavras- chave: Mídia e educação. Televisão Aberta. Educação de Jovens e Adultos.

ABSTRACT: This article aims to discuss the relationship that the students of 5 and 6 years of AYE mode (Youth and Adult Education) of Austricliano Oak School have with Open TV, since these students have yet to complete schooling and belong the lower classes become more vulnerable to media influences. The reflections present in this text are based on not only the theoretical study or references, but part of the data analysis collected in the case study of the process within a qualitative approach. The subjects of the study o7 (seven) students of EJA, used as a data collection tool semi-structured interview individually to each of the participants. The results indicate that students have an informal education relationship to the Open TV, also making up as leisure alternative.

\footnotetext{
I Graduada em Pedagogia pela Universidade do Estado da Bahia (UNEB) - Campus Senhor do Bonfim (BA). Email: renatareinalda@gmail.com.

${ }^{2}$ Professor Adjunto na Universidade Federal do Vale do São Francisco (UNIVASF). Doutor em Educação. Mestre em Educação. Pedagogo. Lider do Grupo Líder do Grupo de Estudos e Pesquisas sobre Pedagogia Universitária e Metodologias Ativas no Semiárido(PUMAS).Email: albano.goes@univasf.edu.br.
} 
Keywords: Media and education. Open TV. Youth and Adult Education.

\section{INTRODUÇÃO}

$\mathrm{Na}$ sociedade contemporânea a comunicação social torna-se um elemento fundamental para possibilitar vias de inovações e modernização, proporcionando então intercâmbio pessoal. Através da inserção de tecnologias cada vez mais avançadas hoje as pessoas podem se comunicar por meio de celulares, assistir televisão, navegar na Internet. Assim, as mídias estão se tornando essenciais para o processo de socialização da população, e indivíduos de todas as idades fazem parte desse novo dinamismo de comunicação que se encontra na sociedade atual.

Dentre os elementos que compõem a mídia em geral, a Televisão Aberta ganha destaque, pois a sua participação na educação é um tema sempre discutido e questionado, alguns consideram a sua influência como ponto positivo, porém outros como ponto negativo.

A primeira centralização da Televisão Aberta foi no Rio de Janeiro e São Paulo durante os anos de 1950, uma programação de tonalidades locais e um telespectador ainda arredio, por falta de hábitos e pelos preços altos dos televisores. Após 1959, a televisão se espraia, com criação de canais em Porto Alegre, em Brasília e no Nordeste, iniciou-se uma importação de programa em grande escala, transformando-se num meio de comunicação de grande acesso aos brasileiros até os dias de hoje (CAPARELLI, I986).

A Televisão Aberta era considerada uma incógnita, algo muito distante, fora da realidade de muitas pessoas, até sua primeira transmissão ir ao ar. Ao longo de seu crescimento foi se tornando como a mídia de maior abrangência na sociedade, se convertendo como a principal fonte de informação e distração para a população do Brasil.

O processo de desenvolvimento dos meios de comunicações e a popularização da linguagem audiovisual foram se desenvolvendo principalmente através da televisão, proporcionando uma grande mudança nas formas de relacionamento do homem com o mundo real e com o imaginário, afetando as suas relações sociais, ultrapassando as 
fronteiras de tempo e espaço, definindo as práticas culturais da sociedade contemporânea (LINHARES, 2007).

O hábito de assistir Televisão Aberta faz parte da cultura atual, na maioria dos lares há uma televisão, uma vez que é um dos aparelhos eletrônicos mais acessíveis aos brasileiros, sendo considerado o principal meio de comunicação de massa no país. As transmissões televisivas dividem-se em canais abertos, disponibilizados de forma gratuita e canais fechados, composta por assinatura, cabo e satélite.

As emissoras abertas trazem conteúdos carregados de informações de acordo com seus interesses, geralmente não possui muitos programas culturais e ricos em conhecimentos, normalmente são repletos por programas que ditam padrões, impõe normas de condutas, manipulam informações, incentivam o consumismo, e fazem com que seus telespectadores sejam induzidos a seguirem seu modelo.

As pessoas de classes menos favorecidas geralmente só podem ter acesso à Televisão Aberta, pois é a opção mais acessível ao seu orçamento, além do mais, para muitos, a Televisão Aberta se torna como instrumento de alienação, seus telespectadores assistem programas para ter uma evasão no pensamento, passam muito tempo assistindo e ficam até mesmo dependentes, pois o televisor serve como meio de entretenimento para relaxar e esquecer-se dos problemas do cotidiano.

Em meio a toda essa imensidade tecnológica que vem se difundindo tão rápido na nossa sociedade contemporânea e com o fácil acesso dos brasileiros para a Televisão Aberta, analisa-se então a sua importância e seu papel na educação, de que maneira os estudantes de Educação de Jovens e adultos- EJA se relacionam com a Televisão Aberta?

A finalidade deste trabalho foi refletir sobre relação dos alunos do $5^{\circ}$ e $6^{\mathrm{O}}$ anos, da modalidade de Educação de Jovens e adultos- EJA da Escola Municipal Austricliano Carvalho de Senhor do Bonfim com a Televisão Aberta. Os objetivos propostos foram alcançados a partir de levantamento teórico para compreender a relação dos alunos da EJA com a Televisão Aberta, desenvolvendo uma análise crítica sobre o impacto que essa exerce no processo de aprendizagem dos alunos jovens e adultos, e por fim analisando a opinião dos mesmos sobre o debate em relação aos conteúdos televisivos. 
Os programas de Televisão Aberta tem uma intencionalidade por trás, e quando os telespectadores não tem noção do que está sendo transmitido fica fácil sua influência. Assim, a classe que na maioria das vezes é mais atingida com esse propósito midiático são pessoas sem escolarização e de classes sociais menos favorecidas, gerando assim muitos telespectadores e poucos leitores, e um público que se enquadra a este perfil são os estudantes de jovens e adultos, uma vez que estes retornam aos bancos escolares por não terem tido a oportunidade de escolarização no período da infância.

A partir da experiência anterior do estágio supervisionado, é que surgiu então a curiosidade de saber se estes alunos da EJA realmente percebem de forma crítica o que é o transmitido pela mídia e qual sentindo que os mesmo dão aos programas transmitidos através da Televisão Aberta, já que muitos utilizam o tempo vago para verem a televisão, visto que através dela é oferecida a sensação de distração e comodidade exigindo pouco esforço para a compreensão.

O tema desperta uma reflexão profunda sobre as consequências que os programas de Televisão Aberta podem levar para a vida das pessoas e consequentemente à educação, analisando a presunção de que a televisão está cada vez mais fazendo parte dos la res dos brasileiros.

O aprofundamento dos estudos sobre como os estudantes da EJA se relacionam com a Televisão Aberta é um tema relevante para o aluno de pedagogia, pois este assunto pertence tanto ao campo da comunicação quanto da educação, uma vez que, acredita-se que a escola independente da série, deve aguçar a visão dos seus alunos em relação à televisão e a outras mídias, conscientizando-os sobre os programas transmitidos pela Televisão Aberta, provocando o senso crítico e democrático.

A partir dessa pesquisa, pode-se entender melhor e mostrar que o papel dos institutos educacionais não é só a formação intelectual do aluno, mas que, necessita cooperar para a formação humana, constituir à um cidadão crítico que argumente frente às intencionalidades trazidas pela mídia, não impedindo de utilizá-las, porém, observando de forma crítica, conscientizada e reflexiva sobre as consequências que os meios de comunicações sociais podem trazer à sociedade e à educação. 


\section{AS TEORIAS QUE EMBASAM A RELAÇÃO MÍdIAS E EDUCAÇÃO DE JOVENS E ADULTOS}

Neste tópico, inicialmente é realizada uma discussão sobre o conceito mídia quanto elemento presente na sociedade atual e que hoje, faz parte da construção educativa das crianças, jovens e adultos. Em seguida, reflete-se sobre a televisão como meio de comunicação social mais acessível para ás famílias brasileira em que será destacada a influência da Televisão Aberta na vida das pessoas das classes sociais menos favorecidas. E para finalizar, é analisada a modalidade de ensino Educação de Jovens e Adultos (EJA), e como esse público que são pertencentes às classes menos favorecidas se tornam mais vulneráveis às influencias de fatores midiáticos, como a Televisão Aberta.

\section{I.I Mídia e educação}

$\mathrm{Na}$ vinculação à contemporaneidade, as pessoas que fazem parte da sociedade contemporânea tentam se atrelar ao conhecimento, inclusão e participação. As crianças, jovens e adultos procuram se adaptar na utilização e compreensão das mídias de informação que estão fazendo parte da atualidade.

Em todos os tempos os seres humanos se ocupam na produção e intercâmbio de conhecimento de conteúdos simbólicos. Desde as mais antigas formas de comunicação gestual e do uso da linguagem até os mais recentes desenvolvimentos da tecnologia, a informação e conteúdos simbólicos tem sido aspectos fundamentais na vida social. Foi com o desenvolvimento de variadas formas de comunicação a partir do século XV até os dias de hoje, que os processos de informações têm passado por diversas transformações e mudanças, e que hoje, fazem parte das características da era moderna (THOMPSON, 20II).

Nas mais variadas áreas que fazem parte do processo social, como, escola, trabalho, lares entre outros, as mídias da comunicação foram tomando espaço por consequência de todo esse avanço tecnológico. As pessoas utilizam as novas vias de comunicação todo tempo para se comunicar, e para se manterem informadas sobre as notícias que giram sobre mundo, uma vez que esses meios de comunicação fazem parte do processo de 
socialização do mundo atual. As mídias de comunicação se tornaram componentes presentes na construção social de cada indivíduo, influencia a construção de sua educação e consequentemente na sua formação de cidadão.

Segundo Peruzzo e Almeida, (2005, p.265):

[...] os meios, especialmente a imprensa, sempre estiveram próximos ao mundo da educação. Não que tomassem as escolas como alvo de suas campanhas de consumo, ou mesmo que abrissem suas portas para escolher e privilegiar os temas educativos, mas porque sempre exerceram o papel de orientadores de opinião.

Os meios de comunicações têm o poder da formação de opinião, pois são responsáveis pela transmissão de informações para a população. As pessoas que tem um vínculo com a mídia recebem muitos tipos de informações, estando corretas ou não. No entanto, estas informações transmitidas pela imprensa podem influenciar a opinião das pessoas em determinados assuntos do mundo atual.

Como qualquer outro produto que se estraga quando mal manuseado, a informação também se corrompe, quando mal codificada, no sentido de um deslize na vinculação de um argumento, de uma manchete, enfim, uma atitude inadequada para os padrões compactuados nas intersubjetividades (PERUZZO e ALMEIDA, 2005).

São muitos obstáculos relacionados à mediação dos meios de comunicação, a padronização e a escassez de conteúdos, o desequilíbrio das informações e a falta de variedade cultural, são consequências que podem ser trazidas por esses elementos midiáticos. As informações vêm ao encontro do cidadão que não questiona, apenas recebe a notícia transmitida como a correta e verdadeira, e os programas fornecidos pela mídia são venerados pelo público que assiste, favorecendo apenas lucro às empresas de comunicação pela grande audiência.

A educação para as mídias ou mídia e a educação, torna-se uma missão da sociedade, do Estado e da escola. É ilusório esperar que as famílias, sobretudo das camadas mais baixas, tenham condições de se conscientizar, e conscientizar seus filhos educando para a leitura crítica das mensagens transmitidas pelos meios de comunicação social (BELLONI, 200I).

Cria-se, portanto, um desafio, gerando a responsabilidade para as instituições e profissionais do campo da educação, para atender os alunos que são alvos dos meios 
tecnológicos. Neste sentido, as possibilidades de conhecimentos construídos através do processo educativo em relação à mídia contribuirão para a aquisição do pensamento crítico e para a formação de cidadãos conscientes. Cabe à escola buscar estratégias e maneiras para equilibrar as disparidades de informações que o acesso aos meios de comunicação está causando na sociedade e na formação educacional dos sujeitos.

\section{I.2 Televisão Aberta}

Quando se fala em comunicações sociais, logo se discute as transmissões de informações. Os meios de comunicação de massa, hoje, se tornaram essenciais para essa nova demanda de conhecimentos e socialização, estando cada vez mais eficazes para o processo de transmissão de informações.

Os meios de comunicação de massa podem ser definidos como produtos de audiência, relacionado principalmente, em termos de volume, escala e velocidade, tal como serviços de correio, um rádio ou uma televisão. Pode-se dizer que tais sistemas são de massa porque transportam muitas mensagens para muito longe. (DIMBLEBY, BURTON, 1990).

Das mais variadas mídias que se encontram na sociedade atual a Televisão Aberta se torna uma das mais influentes e acessíveis aos brasileiros, é um dos meios de comunicação e entretenimento de maior alcance no país.

Diante disso, Belloni (200I, p.32) ressalta que “[...] certos setores da sociedade integram mais facilmente que outros as novas técnicas de produção, estocagem, e transmissão de mensagens ou mesmo meio mais frequentado pela maioria das pessoas em muitos países, a televisão”.

Nessa época, a qual todas as pessoas querem se manter informadas, pode-se dizer que a Televisão Aberta é a principal responsável pela transmissão das informações à população, já que é o meio de comunicação de maior alcance aos brasileiros.

A opinião positiva sobre a televisão como meio de informação e aprendizagem e a assiduidade com que os jovens assistem à televisão são os indicantes mais seguros da importância da televisão na socialização no processo da nova geração. A sociedade perpetua-se através de extenso processo de transmissão de cultura, o saber acumulado da 
ciência e da técnica, os valores, e estruturas simbólicas são apresentadas para as pessoas como imagens e modelos idealizados (BELLONI, 200I).

Os programas transmitidos pela Televisão Aberta fascinam seus telespectadores, introduzindo uma linguagem que seduz o receptor incorporando à sua realidade, trazem conteúdos que podem conduzir novos hábitos para os cidadãos e então a sua cultura pode ser alterada, principalmente pelas emissoras abertas não disponibilizarem de muitos programas culturais e de qualidade, seus programas tem uma intencionalidade que pode atingir o público que assiste.

Os comerciais, programas que são transmitidos pela Televisão Aberta, tentam ativar sinais emocionais armazenados em nosso cérebro, possibilitando que o som da televisão seja subliminar, no sentido em que as pessoas que são influenciadas não estão conscientes da verdadeira fonte daquela influência (SCHWARTZ, 1985).

A televisão é meio de comunicação que traz variadas informações, as pessoas que pertencem às classes sociais menos favorecidas não podem desfrutar de outras redes televisivas, assim, a Televisão Aberta torna-se uma das poucas alternativas para o acesso à informação e distração, porém os conteúdos e informações oferecidos por essas redes gratuitas podem inconscientemente influenciar a vida dos seus telespectadores.

Dessa forma, Belloni (200I, p.72) faz uma ressalva em relação aos brasileiros, "principalmente os que não pertencem às classes sociais mais favorecidas- não sabem utilizarem maneira que lhes seja vantajosa estes instrumentos extraordinários de comunicação contemporâneos, dentre os quais o mais moderno e eficaz é sem dúvida a televisão.

Por ser a televisão um aparelho de fácil acesso à sociedade atual e ter o seu poder influenciador na vida das pessoas, é importante que as pessoas aprendam a utilizar este meio de comunicação de forma astuta, para que, além de distração, possa obter informações de conhecimentos e reflexões podendo ter algum sentido a suas vidas.

Assim, a busca para formação do telespectador se torna um desafio para a educação, uma vez que o papel da escola vai além da formação intelectual do aluno, está atrelado à formação dos cidadãos conscientes e pensantes para que se tornem capazes de se posicionar 
frente às intencionalidades trazidas pelas mídias, e não sejam alvos e aliados dos conteúdos transmitidos pela Televisão Aberta.

\section{I.3 Educação de Jovens e Adultos}

Muitas são as dificuldades que levam uma grande parte de pessoas jovens e adultas a não iniciarem ou prosseguirem com os estudos no período da infância. Questões como, deslocamento, trabalho, falta de condição financeira, a responsabilidade de assumir uma família muito cedo, falta de incentivo, entre outros, formam o quadro das dificuldades encontradas. Por conta disso, muitas pessoas no intuito de suprir essa carência e visando uma qualidade de vida melhor, decidem voltar à escola na fase adulta.

Para compensar ou reverter os reflexos de uma educação incompleta e por vezes defasada, as pessoas buscam através da EJA (Educação de Jovens e Adultos), retomarem a vida escolar, pois, sentem a necessidade de expandir seus conhecimentos e ampliar sua visão de mundo diante das atuais exigências da sociedade.

Tendo em vista essa nova forma de pensar a educação de jovens e adultos, foi criado o Ensino Supletivo contido na Lei de Diretrizes e Bases (LDB) 5.692 de 1971, com o intuito de dar continuidade ao ensino regular daqueles que não o concluíram em idade adequada, além de visar suprir as deficiências, atualizando e aperfeiçoando os conhecimentos dos que puderam seguir o ensino. (HADDAD \& DI PIERRO, 200o).

Atualmente a EJA acontece em escolas públicas municipais no período noturno e recebe alunos com o perfil característico daqueles que por alguma razão tiveram interrompido o processo de escolarização básica. Geralmente esta modalidade educacional de Educação de Jovens e Adultos, trabalha com pessoas que provém de classes sociais menos favorecidas. Segundo Souza e Cunha (s.d, p. 3):

Os alunos dessa modalidade de ensino que buscam a escola pertencem a uma classe social, são pessoas com baixo poder aquisitivo, que consomem, de modo geral, apenas o básico à sua sobrevivência. O lazer fica por conta dos encontros com as famílias ou dos eventos da comunidade. A televisão é apontada como principal fonte de lazer e informação.

Para as pessoas que não tem escolarização, é mais fácil compreender uma situação de uma novela, um programa de distração, do que um discurso ou uma leitura sobre a 
economia, política, desigualdades, entres outros. Dessa forma, os jovens e adultos por muitas vezes ainda não terem uma visão crítica sobre as informações que são transmitidas pela Televisão Aberta, se tornam vulneráveis a esse campo midiático.

As imagens de mundo transmitidas pela mídia formam a consciência de um mundo real a seus telespectadores. Sua influência atinge mediações, como a família, a maioria da população brasileira, passa diretamente para a transmissão oral e pessoal para o rádio e a televisão, sem passar pela palavra escrita (BELLONI, 200I).

O desenvolvimento desses meios de comunicações de massa cresce em abundância no país, e as pessoas destinam mais tempo a assistir televisão do que tentar exercitar o hábito da leitura. Assim, a Televisão Aberta pode causar muitos efeitos sobre o desenvolvimento educativo dos jovens e adultos que buscam a escolarização.

Freire traz uma maneira diferenciada de trabalhar com essas pessoas, direcionando a educação para a formação do sujeito capaz de pensar criticamente sobre a sua posição dentro da sociedade, sobre os seus direitos e deveres, capazes ainda, de reivindicar melhorias e igualdade social. $O$ ensinar se prolonga à produção das condições em que aprender criticamente é possível (FREIRE, 1996).

O ensino estabelecido na sala de aula deve ir além do ensinar conteúdos, faz-se necessário momentos de discussão entre professores e alunos, permitindo o saber dividido, contribuindo para a formação do cidadão crítico, propondo estratégias de reflexão sobre os acontecimentos vivenciados pelos alunos do mundo atual. Dessa forma, cabe o professor orientar criticamente os alunos jovens e adultos, instruindo e refletindo sobre as consequências que podem ser trazidas pela diversidade de informações que circulam no meio social.

Portanto, quando os alunos são instruídos para ler a televisão e são alfabetizados refletidamente pelos professores, tornam-se capazes de compreender as mensagens transmitidas pela Televisão Aberta.

\section{METODOLOGIA}

Entende-se que a metodologia é o caminho de orientação a ser usado no desenvolvimento de uma pesquisa. Diante da curiosidade em relação ao tema abordado, 
buscou-se especificar e mostrar como a pesquisa foi desenvolvida, e como foi possível obter sucesso nos resultados esperados.

A pesquisa apresentada é de análise qualitativa, pois trabalhou com a subjetividade dos sujeitos considerando as variáveis existentes em determinada realidade. Foi avaliado a partir de entrevista semiestruturada, que permitiu a obtenção das informações inteiramente dos membros da análise, e assim conhecer por meio dos próprios jovens e adultos a forma de como se relacionam com a Televisão Aberta.

A pesquisa qualitativa emprega variadas concepções filosóficas, estratégias de investigação, método de coleta, e análise dos dados. Apesar dos processos serem parecidos, os procedimentos qualitativos baseiam-se em dados de texto e imagem, valem diferentes estratégias de investigação e com passos singulares para a análise dos dados. (CRESWELL 2010).

Dessa forma, a pesquisa se apresentou como um meio de descobrir e entender o significado que os indivíduos ou grupos atribuem a um problema social ou humano. Através desse método, pode-se analisar certas atitudes vividas por determinado grupo social gerado por influência da mídia.

\section{I Tipo de pesquisa}

A pesquisa realizada é considerada um estudo de caso por se tratar de uma abordagem metodológica de investigação que buscou compreender fatores midiáticos que poderiam influenciar na educação dos estudantes da EJA. O direcionamento deste método é proposto para a obtenção de descrição compreensão das relações e fatores em cada caso, não contando o número de casos envolvidos.

De acordo o objetivo da investigação, o número de casos a ser investigado pode ser reduzido a um elemento "caso", ou podem também abranger numerosos elementos como subgrupos, grupos, escola, empresa, entre outros. A principal função dessa prática é a explicação de fatos que ocorrem em determinado contexto social, em alguns estudos pode ser facilitados através de formulação de hipóteses e como auxiliares pode ser usado formulário ou a entrevista. (FACHIN, 1993). 
Dessa forma, esse método respondeu os questionamentos sobre o tema abordado, facilitando entendimento do determinado problema social, e assim entender a relação que os alunos jovens e adultos têm com a Televisão Aberta.

\subsection{Lócus}

A pesquisa foi realizada na Escola Municipal Austricliano de Carvalho situada na cidade de Senhor do Bonfim-BA que abrange várias séries do Ensino Fundamental. No período diurno, enquanto o noturno atende o Programa de Educação de Jovens e AdultosEJA formado pelas turmas de $1^{\circ}$ a $2^{\circ}$ ano, $3^{\circ}$ a $4^{\circ}$ ano, $5^{\circ}$ a $6^{\circ}$ ano e a $7^{\circ}$ a $8^{\circ}$ ano. Nesta escola, estão matriculados 103 alunos nas turmas de EJA. A referida escola recebe alunos de diversas localidades pertencentes ao município de Senhor do Bonfim.

\subsection{Sujeitos}

Os sujeitos envolvidos foram o8 (oito) alunos do $5^{\underline{\underline{a}}}$ e $6^{\underline{a}}$ ano da modalidade de Educação de Jovens e Adultos- EJA da Escola Municipal Austricliano de Carvalho. Os alunos são provenientes de classes sociais menos favorecidas, alguns possuem o ensino fundamental incompleto e outros nunca tiveram acesso à educação básica. A escolha dos sujeitos para entrevista semiestruturada foi feita por meio de sorteio, sendo o4 (quatro) do $5^{\mathrm{o}}$ ano e 04 (quatro) do 6으.

\subsection{Instrumento de coleta de dados}

A coleta de dados se deu por meio de uma entrevista semiestruturada, que buscou obter informações sobre a relação que os sujeitos tinham sobre a Televisão Aberta e assim poder se aproximar do objetivo da investigação.

Os passos da coleta de dados abrangem estabelecimentos dos limites para o estudo, à coleta das informações por meio da entrevista semiestruturada, de documentos e materiais visuais, assim como do estabelecimento do protocolo para apontamentos dos dados (CRESWELL, 2010). 
A entrevista semiestruturada foi realizada com cada aluno individualmente, estabelecendo um diálogo focado no assunto, apesar das perguntas terem sido elaboradas, a entrevista foi decorrendo, para que os entrevistados se sentissem mais a vontade, permitindo a recolha de elementos importantes para a pesquisa.

Segundo Lakatos e Marconi (2009, p.202) "As respostas, se possível, devem ser anotadas para maior fidelidade e veracidade das informações. O uso do gravador é ideal, se o informante concordar com a sua utilização.”.

No momento do contato com o entrevistado foi explicado à finalidade da pesquisa e a relevância da sua colaboração, foi sugerida e aceita a opção da gravação para entrevista semiestruturada. As respostas foram gravadas por meio de câmera e depois transcritas por meio de anotações.

Lakatos e Marconi (2009, p.202) ainda ressaltam que:

O registro deve ser feito com as mesmas palavras que o entrevistado usar, evitando-se resumi-las. Outra preocupação é manter o entrevistador atento em relação aos erros, devendo-se conferir as respostas, sempre puder. Se possível, anotar gestos, atitudes e inflexões de voz. Ter em mãos todo o material necessário para registrar as informações.

Apesar de a entrevista ter sido constituída com orientação de questionário composto por ıo (dez) perguntas sequenciais, a entrevista foi realizada de forma livre, através do diálogo, sem desprezar fala e expressões que acontecerem durante o encontro, pois se tornaram informações relevantes para o resultado da pesquisa. A liberdade de expressão ocorrida com os entrevistados possibilitou obter elementos importantes para entender a relação que esses jovens e adultos têm com a Televisão Aberta. Com a gravação das respostas, não houve problemas em relação a esquecer ou distorcer as respostas dos entrevistados.

\subsection{Tabulação}

Após registros e transcrição da entrevista, os dados foram organizados por tabulação, com a organização das perguntas e respostas para que assim as hipóteses pudessem ser evidenciadas. 
As tabulações dos dados foram organizadas em tabelas, possibilitando a maior facilidade de investigação das inter-relações entre os alunos. A parte desse processo técnico de análise estatística permitiu sintetizar os dados da entrevista, permitindo organiza-los graficamente para compreender melhor $e$ avaliar as respostas mais rapidamente. (LAKATOS E MARCONI, 2002).

O processo de tabulação ajudou no agrupamento das variadas respostas dos alunos, facilitando o preparo dos dados para a análise, servindo para avaliar os depoimentos adquiridos através entrevista.

Netto (2008, p.85) “[...] as formas de tabulações, apresentações dos dados e os meios (os instrumentos manuais ou computacionais) são utilizados para facilitar a interpretação e análise dos dados.” A tabulação foi elaborada pelo computador, porém as respostas da entrevista foram escritas manualmente e organizadas.

\subsection{Análise de dados}

A etapa da análise dos dados foi o momento de transformar as respostas transcritas nas

informações cruciais para a análise da pesquisa, significando o momento de considerar as expressões verbais e as discussões sobre o tema debatido.

$\mathrm{Na}$ análise dos dados, o pesquisador entra em maiores detalhes sobre os dados decorrentes do trabalho, a fim de conseguir as respostas a seu problema, estabelecendo as relações entre os dados conseguidos e as suposições formuladas. Estas são comprovadas mediante a análise. (LAKATOS E MARCONI, 2002).

A análise dos dados foi um momento de muito critério e atenção, visto como se tornava o momento da compreensão das variáveis respostas de cada aluno. Dessa forma, após a análise, os dados da pesquisa foram avaliados e concluídos.

\section{UM OLHAR SOBRE OS DADOS}

Para a compreensão dos discursos obtidos na coleta dos dados optou-se por desenvolver a análise das falas, a partir da relação que as mesmas possuem com objetivos propostos nesse trabalho, assim, os questionamentos realizados na entrevista 
semiestruturada permitiram refletir sobre o olhar que esses sujeitos possuem sobre a Televisão Aberta.

Todos os entrevistados foram estudantes $5^{\circ}$ e 6o anos da modalidade EJA da Escola Municipal da Escola Municipal Austricliano de Carvalho, provenientes de classes menos favorecida. Ao iniciar a entrevista semiestruturada, o primeiro questionamento foi para saber os nomes e idades dos alunos. Os entrevistados tinham entre 17 a 51 anos de idade.

Desse modo, no segundo questionamento, abordou-se, junto aos sujeitos, o que mais gostavam de fazer nas horas livres, as respostas foram variadas, porém, a maioria articulava a televisão como maneira de distração.

"Quando tô em casa eu quero distrair, gosto de ficar vendo um filme, gosto muito de jornal, e a tarde até que gosto de ver uma novela. É bom. Quando chego do trabalho, e quero descansar, gosto de ficar assistindo". (ALUNO I, I8 anos).

A falta de alternativa para aproveitar as horas livres, torna-se um dos fatores que levam as pessoas a optarem em assistir a televisão. Geralmente, as pessoas pertencentes à camada de classe baixa, possuem menos opção de lazer, portanto, a televisão se torna uma das poucas escolhas de passatempo e distração.

No terceiro questionamento, perguntou-se quantos aparelhos de televisão os alunos possuíam em casa. A maioria dos alunos possuíam mais de I (uma) televisão em casa. Apesar dos alunos não possuírem uma renda financeira alta, têm em suas casas uma grande quantidade de aparelho de televisão.

O espaço da televisão vem sendo garantido desde muito tempo, competindo com outros meios de comunicação, em toda a casa independente das classes sociais, seu lugar é garantido, sua dominação chega até ser assustadora. (FERREIRA, 2002).

Para dar continuidade a pesquisa, no quarto questionamento da entrevista semiestruturada, foi averiguado quanto tempo em média os alunos passavam assistindo televisão em casa.

"Se fosse pra passar o dia todinho assistindo eu ficava, eu gosto muito de assistir, a quantidade certa de horas eu não sei, mais acho que mais de 4 horas por dia" (ALUNO 3, 20 anos). 
O fascínio dos alunos em assistirem a Televisão Aberta, traz a sensação de comodismo, porém de forma prazerosa para passar o tempo. Percebe-se que, o mundo interno de fantasias que as programações televisivas proporcionam, fazem com que seus telespectadores percam até mesmo a noção da hora.

No quinto questionamento, foi investigado junto aos alunos quais os programas que mais gostavam de assistir. A variedade de programas citados possibilitou uma reflexão do porque que estes alunos destinam tanto tempo para assistir a Televisão Aberta.

"Eu assisto tudo, jornal, DVD, mas a noite costumo assistir mais novela. Mas, gosto muito de assistir o programa do João Kleber, Faustão... tudo." (ALUNO o4, 26 anos).

Assistir as programações fornecida pela televisão Aberta ocupa o tempo livre que os alunos dispõem, porém esse período é preenchido por programas de vários gêneros e de diferentes características, no entanto, as variadas discussões televisivas trazem informações que ocasionam uma espécie de educação não formal aos telespectadores. Entretanto, o resultado dessas informações poderá influenciar em suas relações que estabelecem sobre a vida.

A análise anterior pode ser evidenciada no sexto questionamento, quando foi perguntado aos alunos porque eles gostavam desses programas e o que neles prendiam a sua atenção.

"Assisto esses programas porque ficam disponíveis pra mim, no momento que tô em casa, na hora do descanso. Quando acordo, preparo café aí tá passando o jornal, quando volto pra almoçar, jornal, a noite já é novela. Fico informado de tudo e as novelas ensina sobre a vida”. (ALUNO 7, 30 anos).

As programações impostas pela Televisão Aberta são transmitidas nos horários mais convenientes para que os telespectadores integrem às suas rotinas. As pessoas podem assistir jornal como passatempo, podem ligar a televisão para quebrar a monotonia de preparar um café. As recepções dos produtos da mídia também servem para organizar os horários diários de seus receptores. As pessoas podem adaptar suas rotinas de modo a 
assistir regularmente a certos programas, como um jornal pela manhã, ou reservar um espaço diário semanal para acompanhamento de uma novela (THOMPSON, 200I).

Após a compreensão do processo rotineiro no qual os alunos assistem à televisão, foi debatido o sétimo questionamento sobre o que os alunos aprendiam com esses programas citados transmitidos pela Televisão Aberta.

"Sempre acompanho a televisão, aprendo é tudo, fico alerta da sociedade, e a novela ensina as coisas da vida, a gente fica olhando e aprende como é a vida" (ALUNO 6, 40 anos).

Os programas televisivos envolvem problemas familiares, cotidiano, entre outros, introduz uma linguagem que fascina. Os telespectadores se emocionam diante das programações televisivas, a vivência dos dramas atinge suas emoções, as pessoas acabam se identificando e associando a sua realidade com a ficção mostrada na televisão e essa linguagem é incorporada pelo telespectador. Dessa forma, a Televisão Aberta influencia e acrescenta novos hábitos para a vida dos sujeitos, agregando novos costumes culturais.

Para chegar ao resultado da pesquisa, na oitava questão, averiguou-se junto com alunos, se os mesmo acreditavam que os programas transmitidos pela televisão aberta educam.

"Eles educam porque vejo as coisas que passa na televisão e que é tudo que acontece na vida real, as notícias de tudo passa nela" (ALUNO 02, 5 I anos).

Atualmente, os jovens e adultos acreditam que estão aprendendo ao assistir os programas transmitidos pela Televisão Aberta. Frequentemente os telespectadores constroem um universo fantasioso, uma vez que estes programas reproduzem informações sobre o mundo construindo uma espécie de ilusão e as pessoas acabam se convencendo que estão sendo informados. Essa hipótese foi comprovada no nono questionamento, quando se interrogou os alunos se achavam que os conteúdos que são transmitidos pela Televisão Aberta contribuíam para sua educação e em que sentido.

"Acho que ajudam na minha educação sim, porque assistindo fico mais educado, mais inteligente...eu imagino. A gente aprende tudo, 
como na escola, fico informada das coisas então vou melhorar minha educação" (ALUNO 4, 26 anos).

A maioria dos jovens e adultos consideram que o televisor tem uma legitimidade, como fonte de saber, semelhante à da escola. É, portanto, distinguida como ator importante pelos próprios sujeitos desse complexo de socialização (BELLONI, 200I).

Para concluir a entrevista semiestruturada, o décimo questionamento que foi feito aos alunos, foi no intuito de descobrir se já tinham deixado de fazer algo, como ir pra escola ou viajar, para ficar vendo televisão. A maioria dos alunos responderam que nunca deixaram de fazer algo importante para ficar assistindo a televisão, porém, pelo hábito de assistir, as pessoas acabam se distraindo deixam de fazer seus afazeres domésticos.

"Nunca deixei de fazer nada pra ficar assistindo não. assim, já deixei de fazer só umas coisas em casa, porque fico distraído assistindo e nem vejo a hora passar, mas coisa mais importante não, como vir pra escola, viajar...essas coisas" (ALUNO 8, 40 anos).

Os padrões de assistência à televisão são comumente regulados de tal maneira que

reflitam nas relações de poder entre os membros da unidade doméstica. É uma atividade que permite aos indivíduos se distanciarem de seus contextos práticos de suas vidas cotidianas (THOMPSON, 200I).

\section{CONSIDERAÇÕES FINAIS}

A Televisão Aberta é o meio de comunicação de massa mais influente e poderoso da sociedade moderna, portanto é necessário avaliar as formas de aprendizado relacionado ao conhecimento do estudante frente à televisão.

Considera-se que, os alunos da EJA apresentam uma relação de educação informal com a Televisão Aberta, acreditam que estão aprendendo sobre o mundo e ampliando seu conhecimento, assistem à televisão porque gostam dos programas, se identificam e se mantêm informados. Porém as informações e conteúdos que são transmitidos pela Televisão Aberta acabam criando conceitos e opiniões aos telespectadores.

Os estudantes da EJA também vêm a Televisão Aberta como maneira de distração, uma vez que é um dos meios de comunicação mais acessível e de entretenimento para a 
maior parte das suas horas. Dessa forma, pela precarização da escrita, os alunos da EJA tornam-se vulneráveis às influências da Televisão Aberta, já que assistir as imagens é mais fácil do que interpretá-las e não percebem que os programas abertos são carregados de informações que podem de alguma maneira, influenciar as suas vidas.

O mundo contemporâneo não pode desconhecer os resultados trazidos pela televisão. A escola, como espaço formal de ensino deve adaptar-se a esse novo tempo, buscando estratégias de ensino que agucem o lado crítico do aluno tornando-o capaz de estar à frente das intencionalidades trazidas pela mídia. Esta é com certeza imprescindível na construção do cidadão pensante, ativo, capaz de questionar, analisar criticamente e principalmente mudar determinadas realidades do meio no qual está inserido.

Por fim, essa pesquisa traz contribuições e esclarecimentos no que diz respeito à relação dos alunos da EJA e a Televisão Aberta, no entanto, esse é um campo de pesquisa vasto que está aberto à novas investigações.

\section{REFERENCIAS}

BELLONI, Maria Luiza. O que é mídia-educação. São Paulo: Editora Autores Associados, 2011.

CAPARELli, Sérgio. Comunicação de massa sem massa. 5 ed. São Paulo: Editora Summus. 1986.

CRESWELL, John W. Projeto de pesquisa: métodos qualitativo, quantitativo e misto. 3 ed.Porto Alegre: Editora Sage, 2010.

DIMBLEBY, Richard, BURTON, Graeme. Mais do que palavras. 37 ed. São Paulo: Editora Sumuus, 1990.

FACHIN, Odília. Fundamentos de Metodologia. São Paulo: Editora Atlas, 1993. FERREIRA, Maria Jucilene de Souza. Televisão e formação da criança: Um estudo inicial sobre a exposição da criança à programação televisiva. Fortaleza, 2012. Disponível em: www.uece.br. Acesso em: 29/ori/2014.

FREIRE, Paulo. Pedagogia da Autonomia: Saberes necessários à prática educativa. 34. ed. São Paulo: Editora Paz e Terra, 1996.

HADDAD, Sérgio; PIERRO, Maria Clara. Escolarização de Jovens e Adultos. São Paulo, 200o. Disponível em: http://www.scielo.br. Acesso em: 25/II/2014.

LAKATOS, Eva Maria. MARCONI, Marina de Andrade. Fundamentos de metodologia científica. 6. ed. São Paulo: Editora Atlas, 2009. 
LINHARES, Ronaldo Nunes. Gestão em comunicação e educação: O audiovisual no espaço escolar. Maceió: Editora Edufal, 2007.

NETTO, Alvim Antônio de Oliveira Netto. Metodologia da pesquisa científica. 3. ed. Florianópolis: Editora Visual Books, 2008.

PERUZZO, Cecilia Maria Krohing. ALMEIDA, Fernando Ferreira de. Comunicação para a cidadania. São Paulo. Editora Intercom, 2003.

SCHWARTZ, Tony. Mídia: O segundo Deus. 8 ed. São Paulo: Editora Summus, 1985.

SOUZA, Kezia Costa de, CUNHA, Nathan da Silva. Perfil dos alunos de educação de jovens e adultos de Teresina. Piauí. Disponível em: http://www.ufpi.br. Acesso em: 23/II/20I4.

THOMPSON, Jhon B. A mídia e a modernidade: Uma teoria social da mídia. 3. ed. Rio de Janeiro: Editora Vozes, 20oI. 